- Data Description Article •

\title{
CAS-LSM Datasets for the CMIP6 Land Surface Snow and Soil Moisture Model Intercomparison Project
}

\author{
Binghao JIA ${ }^{* 1}$, Longhuan WANG ${ }^{1,2}$, Yan WANG ${ }^{1,2}$, Ruichao LI ${ }^{1,2}$, Xin LUO ${ }^{1}$, Jinbo XIE ${ }^{1}$, Zhenghui XIE ${ }^{1,2}$, \\ Si CHEN ${ }^{1,2}$, Peihua QIN ${ }^{1}$, Lijuan LI ${ }^{1}$, and Kangjun CHEN ${ }^{1}$ \\ ${ }^{1}$ State Key Laboratory of Numerical Modeling for Atmospheric Sciences and Geophysical Fluid Dynamics, Institute of \\ Atmospheric Physics, Chinese Academy of Sciences, Beijing 100029, China \\ ${ }^{2}$ College of Earth and Planetary Sciences, University of Chinese Academy of Sciences, Beijing 100049, China
}

(Received 3 September 2020; revised 4 December 2020; accepted 6 January 2021)

\begin{abstract}
The datasets of the five Land-offline Model Intercomparison Project (LMIP) experiments using the Chinese Academy of Sciences Land Surface Model (CAS-LSM) of CAS Flexible Global-Ocean-Atmosphere-Land System Model Grid-point version 3 (CAS FGOALS-g3) are presented in this study. These experiments were forced by five global meteorological forcing datasets, which contributed to the framework of the Land Surface Snow and Soil Moisture Model Intercomparison Project (LS3MIP) of CMIP6. These datasets have been released on the Earth System Grid Federation node. In this paper, the basic descriptions of the CAS-LSM and the five LMIP experiments are shown. The performance of the soil moisture, snow, and land-atmosphere energy fluxes was preliminarily validated using satellite-based observations. Results show that their mean states, spatial patterns, and seasonal variations can be reproduced well by the five LMIP simulations. It suggests that these datasets can be used to investigate the evolutionary mechanisms of the global water and energy cycles during the past century.
\end{abstract}

Key words: LS3MIP, CMIP6, CAS FGOALS-g3, CAS-LSM, soil moisture, snow

Citation: Jia, B. H., and Coauthors, 2021: CAS-LSM datasets for the CMIP6 Land Surface Snow and Soil Moisture Model Intercomparison Project. Adv. Atmos. Sci., 38(5), 862-874, https://doi.org/10.1007/s00376-021-0293-x.

Database profile

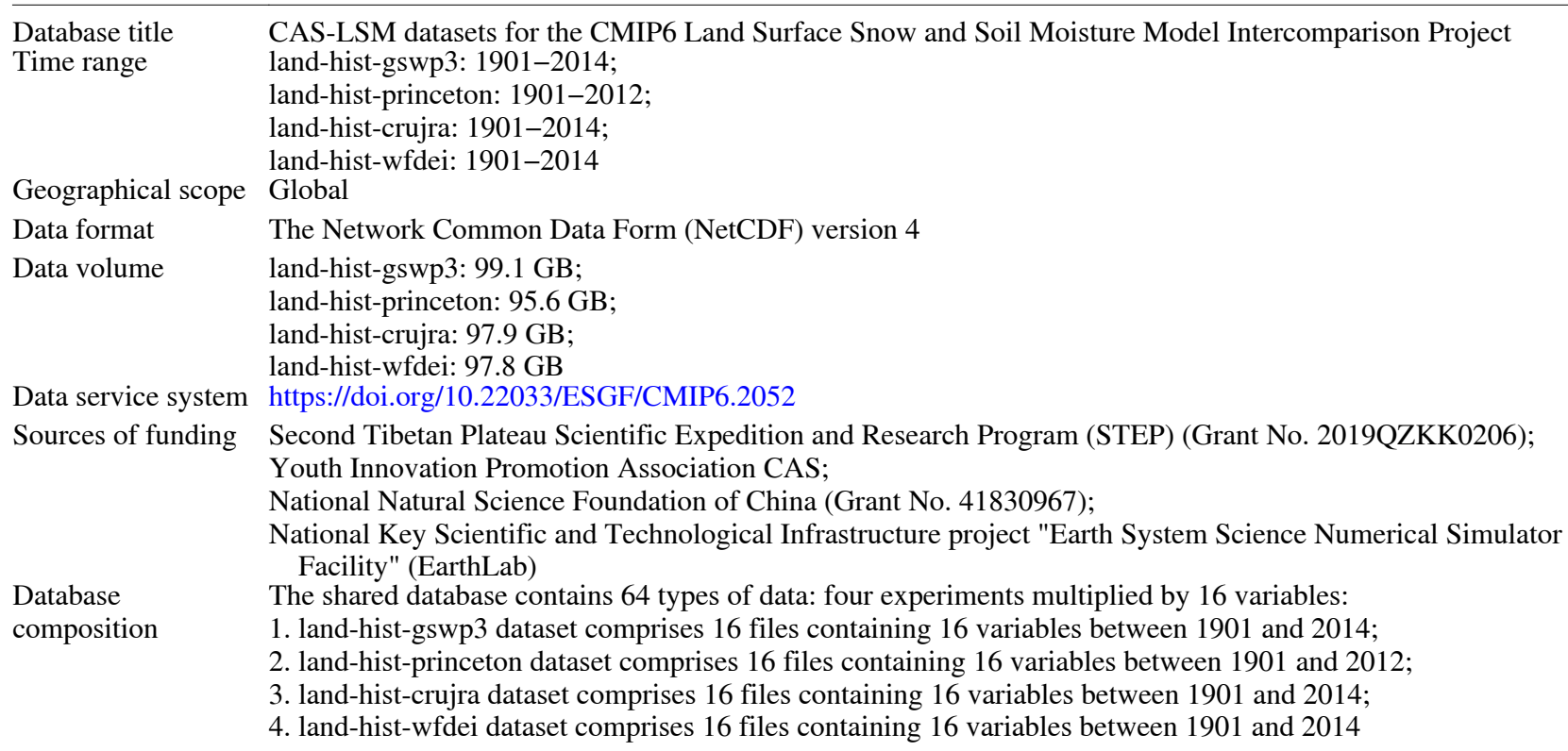

* Corresponding author: Binghao JIA

Email: bhjia@mail.iap.ac.cn

\section{Introduction}

Land surface processes, including soil moisture, snow, 
vegetation, runoff, and sensible and latent heat fluxes, continue to play an important role in the state-of-the-art Global Climate Models (GCMs) and Earth System Models (ESMs) (van den Hurk et al., 2016). As the land component of GCM and ESM, land surface models (LSMs) have seen considerable development during recent decades (van den Hurk et al., 2011). Moreover, there have been several LSM intercomparison projects on an international level (Boone et al., 2009; van den Hurk et al., 2011). The Land Surface, Snow and Soil moisture Model Intercomparison Project (LS3MIP; van den Hurk et al., 2016) is designed to allow the climate modeling community to address the challenges regarding the representation of land surface processes in the GCMs and ESMs and to enhance the understanding of related climate feedbacks (van den Hurk et al., 2016). It is also part of the sixth phase of the Coupled Model Intercomparison Project (CMIP6; Eyring et al., 2016). LS3MIP consists of a series of land-offline experiments driven by different land surface forcing datasets, referred to as LMIP (Land-offline MIP), and a variety of coupled model simulations, known as LFMIP (Land Feedback MIP). The goal of the LMIP experiments is to provide for a widespread evaluation of land surface, snow, and soil moisture, and to diagnose systematic biases in the land components of current GCMs and ESMs (van den Hurk et al., 2016). There are 16 Earth system modeling groups participating in LS3MIP (van den Hurk et al., 2016). Several studies have examined the preliminary performances of LMIP experiments within the framework of LS3MIP (Decharme et al., 2019; Lawrence et al., 2019; Li et al., 2019).

The Land Surface Model for the Chinese Academy of Sciences (CAS-LSM) was developed at the Institute of Atmospheric Physics (IAP), CAS (Xie et al., 2018a; Wang et al., 2019; Wang et al., 2020b). It is the land component of the climate system models of CMIP6: the CAS Flexible GlobalOcean-Atmosphere-Land System Model Grid-point version 3 (CAS FGOALS-g3), which was developed at the State Key Laboratory of Numerical Modeling for Atmospheric Sciences and Geophysical Fluid Dynamics (LASG) of the Institute of Atmospheric Physics (IAP), CAS (Li et al., 2020). Based on the experiment design for CMIP6 (Eyring et al., 2016), many CMIP6 experiments based on CAS FGOALSg3 have been conducted, including the Diagnostic, Evaluation, and Characterization of Klima (Li et al., 2020), historical simulations, Scenario Model Intercomparison Project (Pu et al., 2020), Flux-Anomaly-Forced Model Intercomparison Project (Wang et al., 2020a), Ocean Model Intercomparison Project (OMIP; Lin et al., 2020), Paleoclimate Modeling Intercomparison Project (Zheng et al., 2020), and so on. These data sets have been published online in the Earth System Grid Federation (ESGF).

The LMIP simulations based on the CAS-LSM of CAS FGOALS-g3 were completed in 2019 and these datasets were submitted to the ESGF (https://esgf-node.llnl.gov/ projects/cmip6/) in April 2020. We will provide a comprehensive introduction of the LMIP datasets from CAS-LSM for a variety of users in this study. The model descriptions and experimental designs are explained in Section 2. Section 3 presents a preliminary evaluation of the LMIP experiments for CAS-LSM. Section 4 provides the data records and usage notes.

\section{Model and experimental designs}

\subsection{Model descriptions}

CAS-LSM was developed based on the LSM, Community Land Model version 4.5 (CLM4.5; Oleson et al., 2013), by simultaneously incorporating human water regulation (HWR), and changes in the depth of frost and thaw fronts (FTFs) (Xie et al., 2018a). As the land model for the Community Earth System Model 1.2, CLM4.5 was developed by the National Center for Atmospheric Research. It can represent several aspects of the land surface, including land biogeophysics, hydrological cycle, biogeochemistry, and ecosystem dynamics. For a detailed description of the biogeophysical and biogeochemical parameterizations and numerical implementation of CLM4.5, please see Oleson et al. (2013). The main changes of CASLSM compared with CLM4.5, including the descriptions of HWR and the changes in FTFs, are provided in the present study.

An HWR scheme was incorporated into CLM4.5 as a submodel (Zou et al., 2015; Zeng et al., 2016, 2017), which included a human water exploitation module and water consumption from agriculture, industry, and domestic use (Xie et al., 2018a). Water withdrawal includes groundwater pumping and surface water intake. Groundwater pumping indicates extracting water from an aquifer while surface water withdrawal is the extraction of water from rivers. Groundwater pumping is expressed as

$$
W^{\prime}=W-q_{\mathrm{g}} \Delta t,
$$

where $W^{\prime}$ and $W$ are the water storage in an aquifer before and after groundwater withdrawal, $\Delta t$ is the time step, $q_{\mathrm{g}}$ is the groundwater pumping rate. The change in the groundwater table can be described as

$$
h^{\prime}=h-\frac{q_{\mathrm{g}} \Delta t}{s},
$$

where $h^{\prime}$ and $h$ are the groundwater table before and after groundwater pumping, $s$ is the aquifer-specific yield. Surface water intake is expressed as

$$
S^{\prime}=S-q_{\mathrm{s}} \Delta t,
$$

where $S^{\prime}$ and $S$ are surface water storage in an aquifer before and after surface water intake. Based on the actual water consumption data, the irrigation water was assumed to be the net water input into surface soil (Zeng et al., 2016, 2017).

The soil temperature of CLM4.5 was calculated using the second law of heat conduction. However, it could not 
provide an exact soil depth at which the temperature is $0^{\circ} \mathrm{C}$. A new one-directional FTF scheme in a soil profile has been incorporated into the soil temperature module of CASLSM (Xie et al., 2018a; Gao et al., 2019). The FTF calculation is expressed as

$$
z_{1}=\sqrt{\frac{2 \lambda\left(T-T_{\mathrm{f}}\right) t}{L \theta}}
$$

where $z_{1}$ is the depth of FTFs and 1 is the freezing or thawing front, $\lambda$ is soil thermal conductivity, $t$ is freezing/thawing duration, $T$ is the average temperature at the soil surface, $T_{\mathrm{f}}$ is the freezing/thawing point temperature, $L$ is the volumetric latent heat of fusion, and $\theta$ is soil water content. Detailed information on the FTF scheme can be found in Gao et al. (2019).

\subsection{Experimental designs}

LS3MIP provides a detailed experimental protocol for different land surface models, including meteorological forcing datasets, ancillary data (e.g., land use and land cover changes, surface parameters, and $\mathrm{CO}_{2}$ concentration), spinup, and experimental designs. In this study, five meteorological forcing datasets were used to force the offline CASLSM. The forcing datasets contain precipitation, solar radiation, air temperature, specific humidity, and wind speed. General information on the five datasets is summarized in Table 1.

The first is the Global Soil Wetness Project forcing dataset (GSWP3; Kim, 2017), which is the default atmospheric forcing dataset for the LS3MIP (van den Hurk et al., 2016) land-offline simulations. It is a three-hourly global forcing product with a $0.5^{\circ}$ longitude-latitude grid (http://hydro.iis. u-tokyo.ac.jp/GSWP3/). GSWP3 was generated through the dynamical downscaling of the 20th Century Reanalysis version 2 (Compo et al., 2011) using a spectral nudging technique (Yoshimura and Kanamitsu, 2008). The precipitation, air temperature, longwave radiation, and shortwave radiation was bias-corrected using the Climate Research Unit (CRU) TS v3.21, Global Precipitation Climatology Center (GPCC) v7, and the Surface Radiation Budget datasets, respectively. The GSWP3 v1.0.6 dataset (Kim, 2017) for the time period 1901-2014 was used in this study.
The PRINCETON dataset (Sheffield et al., 2006) was generated by combining the National Centers for Environmental Prediction (NCEP) reanalysis with the CRU and satellite-based precipitation products, including the Global Precipitation Climatology Project and Tropical Rainfall Measuring Mission products. The Princeton version 2.2 dataset with a 3-hourly resolution and a $0.5^{\circ} \times 0.5^{\circ}$ latitude-longitude grid from 1901 to 2012 was used in this study.

The CRUNCEP is a 6-hourly and $0.5^{\circ}$ global meteorological forcing dataset, which is a combination of two datasets: the CRU TS v3.2 monthly $0.5^{\circ}$ climate dataset and the NCEP 6-hourly $2.5^{\circ}$ reanalysis dataset. The NCEP was only used to calculate diurnal and daily anomalies while their monthly mean values were bias-corrected using the CRU data. The precipitation, temperature, solar radiation, and relative humidity are all based on the CRU data while longwave radiation, pressure, and wind speed are directly interpolated from NCEP to a $0.5^{\circ} \times 0.5^{\circ}$ grid. Here we used CRUNCEP version 7 (Viovy, 2018).

The CRUJRA is a 6-hourly meteorological forcing dataset produced by the CRU at the University of East Anglia (Harris, 2019). The variables are provided on a $0.5^{\circ} \times 0.5^{\circ}$ grid. It is generated using the combination of the Japanese Reanalysis data (JRA) and the CRU TS 4.03 data. The CRUJRA version 2.0 covering the time period from 1901 to 2014 was used in this study.

The WATCH forcing data (WFD) for 1958-2001 were generated using the European Centre for Medium-range Weather Forecasts ERA-40 reanalysis whereas the data from 1901 to 1957 were based on the reordered ERA-40 dataset. Bias corrections have been applied to the WFD dataset using the CRU and GPCC data. More detailed information about the WFD can be found in Weedon et al. (2011). The WFDEI forcing data were generated using the same algorithm as the WFD forcing data based on the ERAInterim reanalysis (Weedon et al., 2014). However, the WFDEI dataset only covers years from 1979 to 2014. The other data from 1901 to 1978 are provided by the WFD. Both the WFD and WFDEI data are provided on a $0.5^{\circ}$ grid and $3 \mathrm{~h}$ intervals.

The land use and land cover data for CAS-LSM were generated by combining satellite land cover descriptions and past transient land use time series from the Land Use Harmon-

Table 1. Descriptions of the five land-offline experiments of CAS-LSM from CAS FGOALS-g3.

\begin{tabular}{|c|c|c|c|c|c|c|}
\hline Experiment/Variable & Forcing & Period & Interval & Spatial & Domain & Reference \\
\hline land-hist-gswp3 & GSWP3 & $1901-2014$ & 3-hourly & $0.5^{\circ} \times 0.5^{\circ}$ & Global & Kim (2017) \\
\hline land-hist-princeton & PRINCETON & $1901-2012$ & 3-hourly & $0.5^{\circ} \times 0.5^{\circ}$ & Global & Sheffield et al. (2006) \\
\hline land-hist-cruncep & CRUNCEP & $1901-2014$ & 6-hourly & $0.5^{\circ} \times 0.5^{\circ}$ & Global & Viovy (2018) \\
\hline land-hist-crujra & CRUJRA & $1901-2014$ & 6-hourly & $0.5^{\circ} \times 0.5^{\circ}$ & Global & Harris (2019) \\
\hline land-hist-wfdei & WFDEI & $1901-2014$ & 3-hourly & $0.5^{\circ} \times 0.5^{\circ}$ & Global & Weedon et al. (2011) \\
\hline soil moisture & ESA CCI & $1979-2014$ & daily & $0.25^{\circ} \times 0.25^{\circ}$ & Global & Gruber et al. (2019) \\
\hline snow cover & MODIS & $2001-2014$ & monthly & $0.05^{\circ} \times 0.05^{\circ}$ & Global & Hall and Riggs (2015) \\
\hline latent and sensible heat fluxes & FLUXCOM & $2001-2014$ & monthly & $0.5^{\circ} \times 0.5^{\circ}$ & Global & Jung et al. (2019) \\
\hline terrestrial water storage & GRACE & 2003-2014 & monthly & $0.25^{\circ} \times 0.25^{\circ}$ & Global & Save (2019) \\
\hline
\end{tabular}


ization 2 (LUH2; Hurtt et al., 2011) dataset (https://luh. umd.edu). The irrigation dataset (Zeng et al., 2016, 2017) was generated by combining the Food and Agriculture Organization of the United Nations (FAO) global water information and the Global Map of Irrigation Areas version 5.0 data (Siebert et al., 2005). Human water use data were calculated using the methods provided in our previous studies (Zou et al., 2015; Zeng et al., 2017; Wang et al., 2019).

The LMIP experiments of CAS-LSM followed the protocol of LS3MIP (van den Hurk et al., 2016), which are land-offline simulations forced by the different atmospheric forcing datasets. The spin-up was conducted by recycling the climate mean and variability of the meteorological forcing over 20 years (1901-20) to reach equilibrium. All the five simulations had the same horizontal spacing of $0.9^{\circ}$ (latitude) $\times 1.25^{\circ}$ (longitude). The time period of atmospheric forcing was 114 years (1901-2014) except for PRINCETON (1901-2012). All atmospheric forcing datasets were bilinearly interpolated to the same spatial resolution as the model simulations.

\subsection{Observations}

To validate the performance of the five LMIP simulations from CAS-LSM, satellite-based soil moisture, snow, sensible and latent heat fluxes, and terrestrial water storage (TWS) observations or merged products were used in this study. A merged multi-decadal satellite-based soil moisture product derived from the European Space Agency Water Cycle Multi-mission Observation Strategy and Climate Change Initiative project (ESA CCI, www.esa-soilmoisturecci.org) was used for comparison with the model-based surface soil moisture. It was generated by blending seven passive-based and four active-based soil moisture products (Dorigo et al., 2017; Gruber et al., 2017, 2019). We used the ESA CCI version 4.7 combined product with a $0.25^{\circ}$ resolution from 1979 to 2014 at a daily temporal resolution.

The monthly mean snow cover product derived from the Moderate Resolution Imaging Spectroradiometer (MODIS) was used to validate the model-based snow cover fraction (SCF) simulations. We used the MODIS Climate Modeling Grid Version 6 (Hall and Riggs, 2015) product with a $0.05^{\circ}$ resolution from 2001 to 2014 (https://nsidc.org/ data/MOD10CM/versions/6).

This study also used the data-driven global gridded land-atmosphere energy flux product (hereinafter FLUXCOM; Jung et al., 2019) to validate the latent and sensible heat fluxes. The FLUXCOM product was generated by merging energy flux measurements from FLUXNET eddy covariance towers with remote sensing data based on a machine learning method. In all, there were 27 FLUXCOM datasets which used nine machine learning methods and three energy balance corrections. The median values of the 27 monthly mean products with a spatial resolution of $0.5^{\circ} \times 0.5^{\circ}$ for the period $2001-14$ were used in this study.

The TWS derived from the Gravity Recovery and Climate Experiment (GRACE) satellite observations (Tapley et al., 2004) were used to evaluate the model simulations. We chose the GRACE RL06 mascon product (http://www2.csr. utexas.edu/grace/RL06_mascons.html) (Save et al., 2016; Save, 2019), which is the latest version of GRACE. This study also used the monthly TWS anomaly (TWSA) data which is computed relative to the mean of 2004-2009. The TWSA data covered the period 2003-2014 and had a spatial resolution of $0.25^{\circ}$.

To be consistent with the CAS-LSM simulations, all of these observations, including ESA CCI, MODIS, FLUXCOM, and GRACE data, were re-gridded to the same resolution as the model-based simulations $\left(0.9^{\circ} \times 1.25^{\circ}\right)$ before validation using conservative remapping.

\section{Preliminary validation}

\subsection{Soil moisture}

The basic results of the five LMIP experiments underwent preliminary validation before the submission of all the datasets. Figure 1 shows the annual means of surface soil moisture $(0-10 \mathrm{~cm})$ at the global scale derived from five LMIP simulations and their differences with the ESA CCI product. The comparisons were made from 1979 to 2014 and all the model simulations in Fig. 1 have been masked while the ESA CCI soil moisture data were available. Compared with ESA CCI, all five LMIP simulations show similar broad patterns of surface soil moisture, with high spatial correlation coefficients ranging between 0.934 and 0.941. However, the model-based simulations show drier soil in northeastern Asia and wetter soil in northwestern Asia than ESA CCI. CRUNCEP has lower soil moisture over northeastern Asia than the other four simulations or the ESA CCI product. In addition, the spatial distributions of the Pearson correlation coefficient and root mean square deviation (RMSD) between five LMIP simulations and the ESA CCI product were presented in Figs. S1 and S2 [in the electronic supplementary material (ESM)], respectively. It is found that these simulations show high temporal correlations and low RMSD in most areas except for northern high latitudes, which may be related to the poor data quality of satellite-retrieved soil moisture products under frozen conditions (Dorigo et al., 2017).

As shown in Figs. $2 a$ and $2 b$, the five LMIP simulations show significantly increasing trends in surface and root zone soil moisture during the past 36 years (1979-2014) due to significantly increased precipitation (Fig. 2c). Compared with the other four simulations, GSWP3 has the wettest surface and root zone soil moisture due to higher precipitation. In contrast, CRUNCEP shows the lowest soil moisture, which may be related to the lower precipitation (Fig. 2c) and higher temperature (Fig. 2d). Clear differences in soil moisture can be observed among the five LMIP simulations; however, they are mainly systematic biases and the temporal correlation coefficients for the five datasets are high (over 0.9), indicating that the five LMIP simulations have consistent temporal variations in soil moisture. Additionally, all five forcing data sets show 

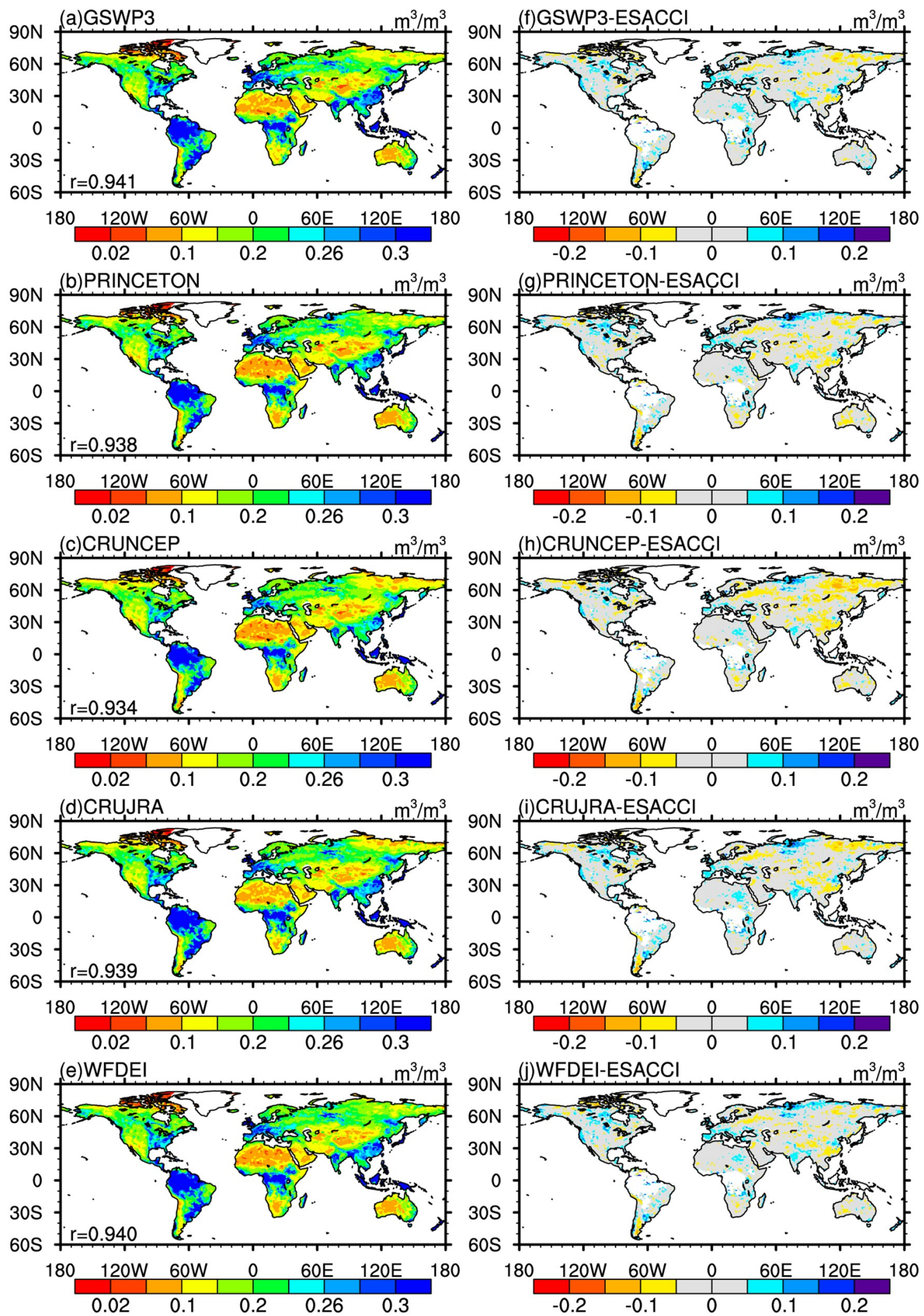

Fig. 1. The spatial patterns of surface soil moisture (top $10 \mathrm{~cm}$ ) derived from five LMIP simulations (GSWP3, PRINCETON, CRUNCEP, CRUJRA, and WFDEI) and their differences with the ESA CCI soil moisture product between 1979 and 2010. $r$ in the left column indicates the spatial correlation coefficient of the model-based simulations with ESA CCI. 
(a) Surface soil moisture

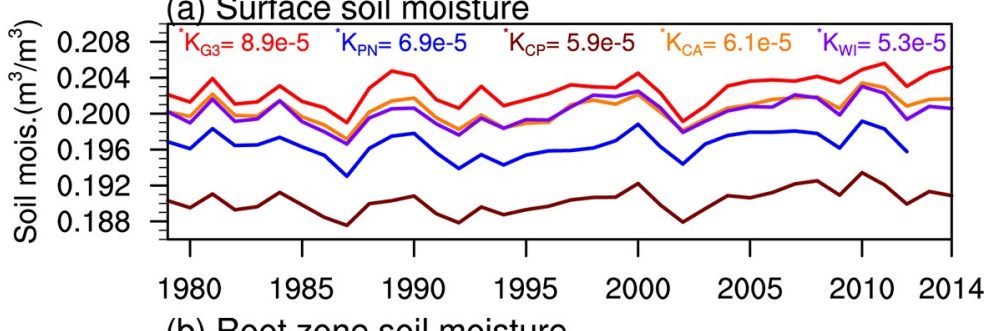

(b) Root zone soil moisture

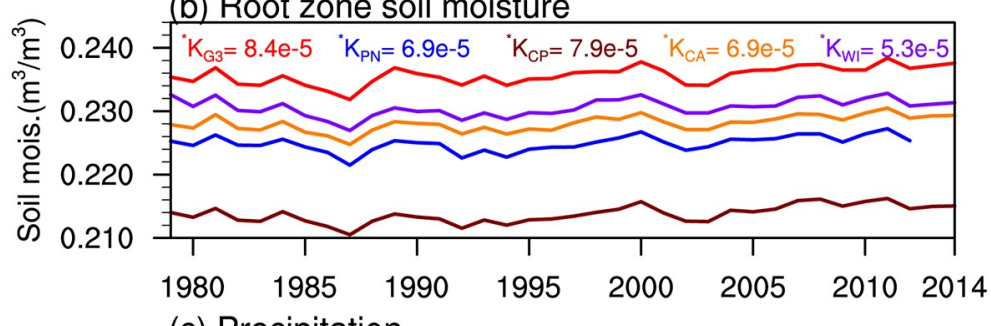

(c) Precipitation
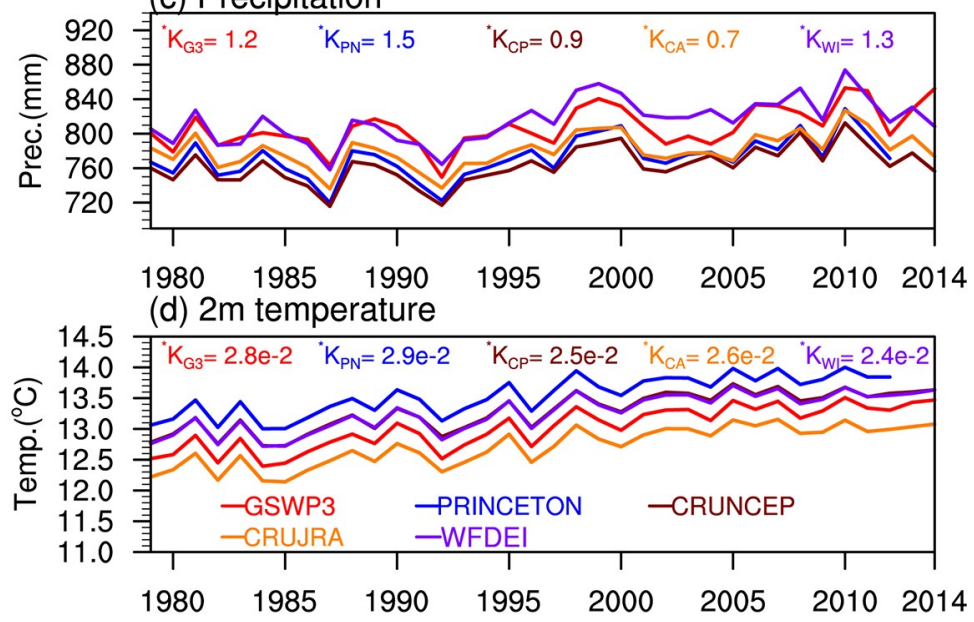

Fig. 2. Interannual variations of (a) surface soil moisture (top $10 \mathrm{~cm}$ ), (b) root zone soil moisture $(0-200 \mathrm{~cm})$, (c) precipitation, and (d) $2 \mathrm{~m}$ temperature for the five LMIP simulations (GSWP3, PRINCETON, CRUNCEP, CRUJRA, and WFDEI) averaged globally (excluding Greenland) between 1979 and 2014. $K$ is the trend for soil moisture $\left(\mathrm{m}^{3} \mathrm{~m}^{-3} \mathrm{yr}^{-1}\right)$, precipitation $\left(\mathrm{mm} \mathrm{yr}^{-1}\right)$, and temperature $\left({ }^{\circ} \mathrm{C} \mathrm{yr}^{-1}\right)$ calculated using the Mann-Kendall test method; the subscript of K: G3 (GSWP3), PN (PRINCETON), CP (CRUNCEP), CA (CRUJRA), and WI (WFDEI). The asterisk represents the statistically significant trends $(p<0.05)$.

similar spatial distributions of the air temperature (not shown), since they were all bias corrected to different versions of CRU products. In contrast, the annual precipitation shows some differences. WFDEI shows slightly larger precipitation than GSWP3 over most land areas, while CRUNCEP and PRINCETON shows lower values globally (Wang et al., 2020b). This is because the precipitation of GSWP3 and WFDEI was biased corrected to different versions of GPCC products with different approaches to under-catch correction while CRUNCEP, CRUJRA, and PRINCETON were bias-corrected to different versions of CRU products. Interannual variations in precipitation and the $2 \mathrm{~m}$ temperature are presented in Figs. $2 \mathrm{c}$ and $2 \mathrm{~d}$, respectively. The global mean land precipitation shows a consistent increasing trend $\left(0.7-1.5 \mathrm{~mm} \mathrm{yr}^{-1}, p<0.05\right)$ concurrent with a rapid warming trend $\left(0.024^{\circ} \mathrm{C} \mathrm{yr}^{-1}-0.029^{\circ} \mathrm{C} \mathrm{yr}^{-1}, p<0.05\right)$ in the five datasets.

\subsection{Snow}

The changes in snow over the Northern Hemisphere $\left(\mathrm{NH}\right.$, poleward of $\left.25^{\circ} \mathrm{N}\right)$ were examined using the satellitebased SCF. The climatological seasonal cycles in Fig. 3 were computed for 2001-2014, but only autumn (SON), winter (DJF), and spring (MAM) seasons were presented. In general, the SCF estimates from the five LMIP simulations capture the spatial patterns of the MODIS-derived SCF product well, with spatial correlation coefficients of over 0.957 for the three seasons. However, differences could be observed in the areas with complex terrain, for example, in the western United States, and on the Tibetan Plateau. This may be due to sub-grid scale snow variations, in complex terrain, not being accurately represented in the CAS-LSM, 
(a)MODIS

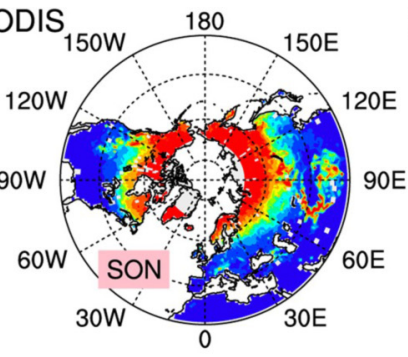

(d)GSWP3

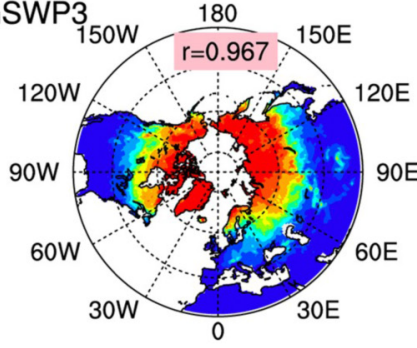

(g) PRINCETTON $180,150 \mathrm{E}$
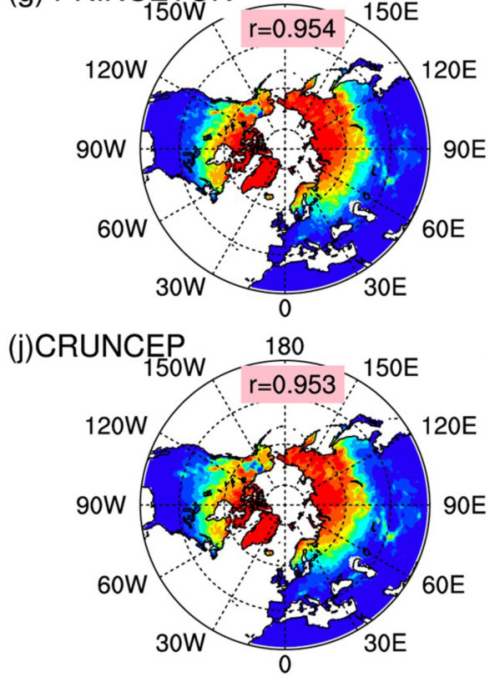

(m)CRUJRA $\frac{180}{r=0.973}$ 150E

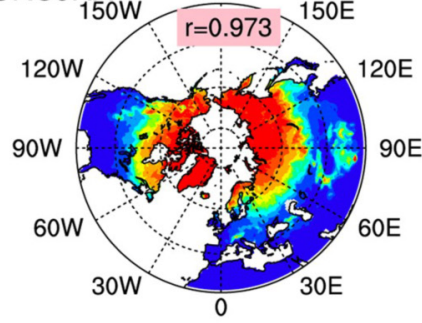

(p)WFDEI

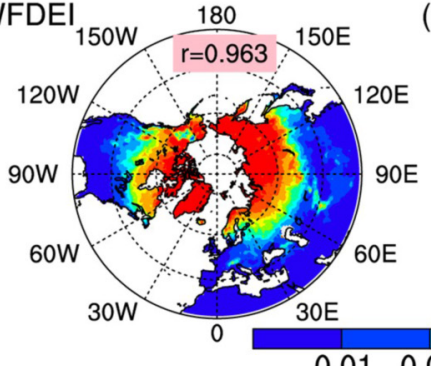

(b)MODIS

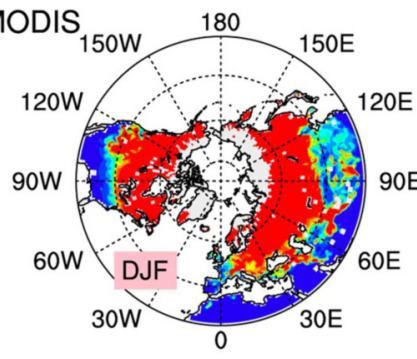

(e)GSWP3

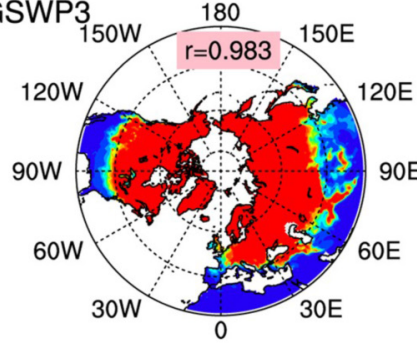

(h)PRINCETON $180 \quad 150 \mathrm{E}$

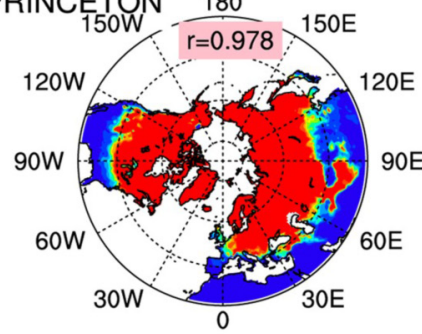

(k)CRUNCE

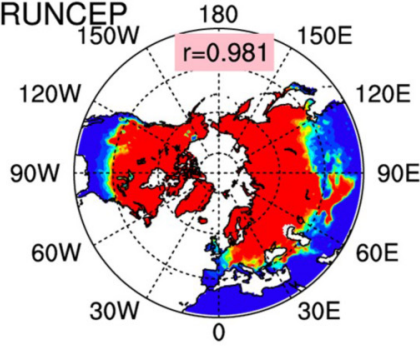

(n)CRUJRA

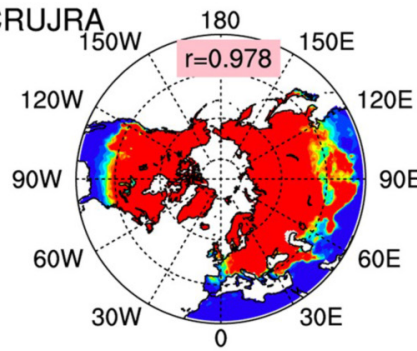

(q)WFDE

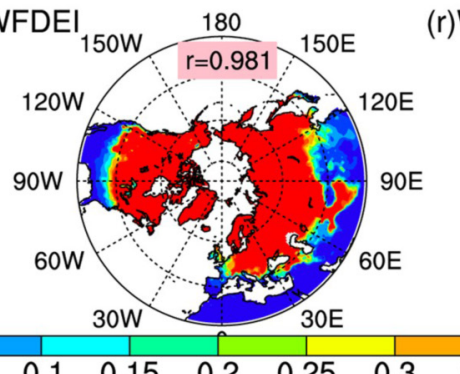

(c)MODIS

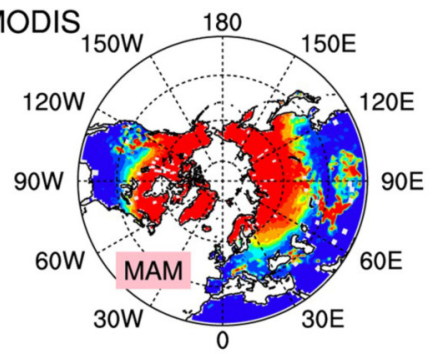

(f)GSWP3

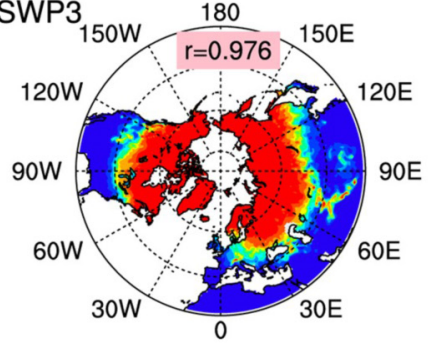

(i)PRINCETON $\frac{180}{150 \mathrm{~W}=0.975}{ }^{150 E}$

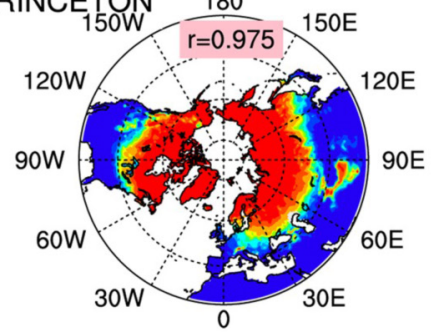

(I)CRUNCEP $, \frac{180}{150 \mathrm{~W}}, \mathrm{r}=0.977,150 \mathrm{E}$

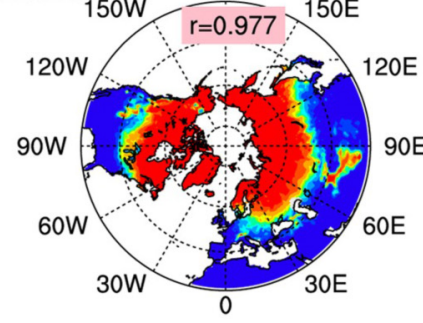

(o)CRUJRA $\frac{180}{150 \mathrm{~W}=0.979} \times 150 \mathrm{E}$

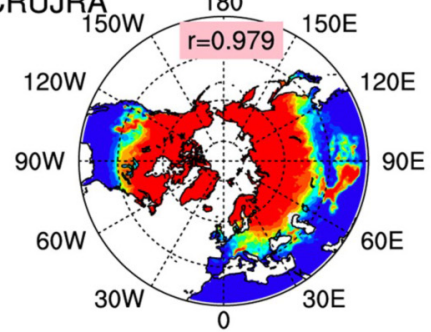

(r)WFDEI ${ }_{150 \mathrm{~W}}, \frac{180}{\mathrm{r}=0.977}{ }^{150 \mathrm{E}}$
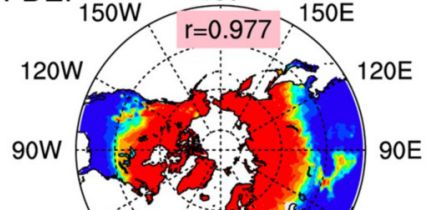

$60 \mathrm{w}$

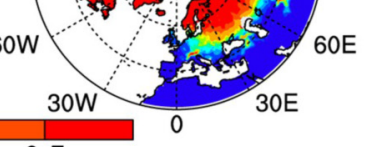

Fig. 3. Northern Hemispheric distributions of the mean seasonal snow cover fractions from (a-c) MODIS and $(\mathrm{d}-\mathrm{r})$ the five LMIP simulations during autumn (SON, left column), winter (DJF, middle column), and spring (MAM, right column) between 2001 and 2014. The $r$ is the spatial correlation coefficient of the model-based simulations with MODIS. 
including blowing snow and the effect of aspect and slope on snow accumulation and melting (Xie et al., 2018b). The SCF is positively biased over the Tibetan Plateau, Alaska, and parts of western Siberia. In contrast, all five LMIP simulations tend to overestimate the SCF over most of the middle latitudes of Asia, Europe, and North America. In addition, there are larger positive biases over the high latitudes across the central and eastern United States and northern Europe during winter and spring. Detailed comparison results with ground measurements and satellite-based observations including SCF, snow depth, and snow water equivalent can be found in Wang et al. (2020b).

\subsection{Latent and sensible heat fluxes}

We validated the spatial patterns of latent and sensible heat fluxes from the five LMIP simulations using the FLUXCOM product. All model simulations show acceptable agreement with the spatial variation of sensible heat flux from FLUXCOM (Fig. 4), with correlation coefficients ranging between 0.831 and 0.905 . However, a systematic overestimation is observed over parts of the northern low latitudes and most of the Southern Hemisphere for PRINCETON (Fig. 4g), CRUNCEP (Fig. 4h), CRUJRA (Fig. 4i), and WFDEI (Fig. 4j). All five simulations exhibit lower sensible heat fluxes over the northern high latitudes than FLUXCOM. Sim-
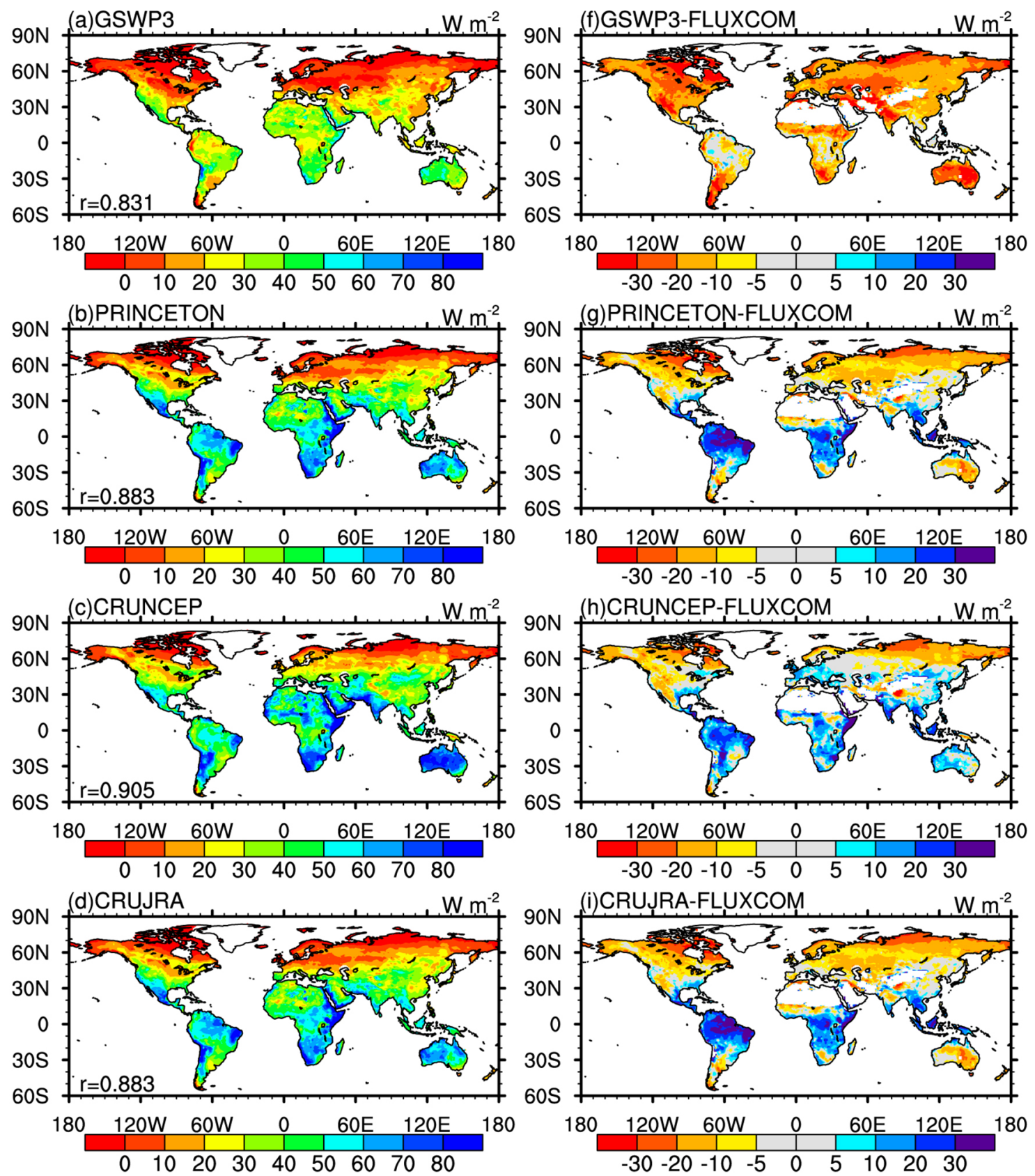

Fig. 4. Spatial patterns of sensible heat flux from the five LMIP simulations (GSWP3, PRINCETON, CRUNCEP, CRUJRA, and WFDEI) and their differences with FLUXCOM between 2001 and 2014. The $r$ in the left column indicates the spatial correlation coefficient of the model-based simulations with FLUXCOM. 

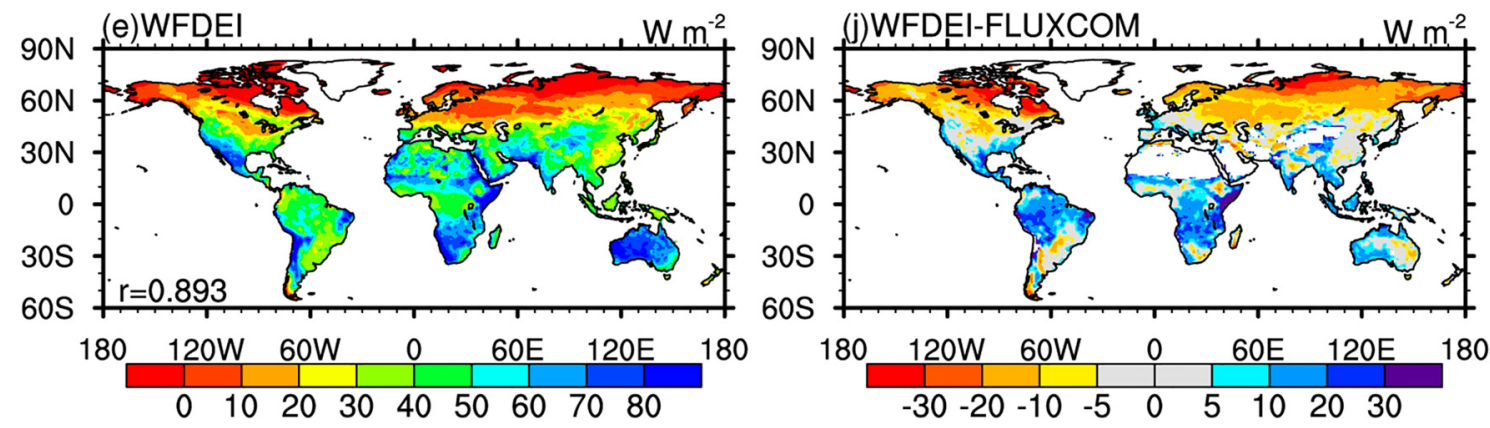

Fig. 4. (Continued).

ulations with GSWP3 appear to have sensible and latent heat fluxes that are generally higher across the globe than the other four simulations and FLUXCOM. As shown in Fig. 5, all LMIP simulations capture the spatial pattern of the latent heat flux very well, with spatial correlation coefficients around 0.96. Model simulations show slight underestimations over most of the globe. This is particularly visible over the northern parts of South America and southern Africa. In addition, some systematic overestimations are found over Australia and the Tibetan Plateau.

\subsection{Terrestrial water storage}

TWS is the sum of water stored above and underneath the surface of the earth (Syed et al., 2008; Zeng et al., 2008) and plays an important role in Earth's climate system (Zeng et al., 2008; Jia et al., 2020). The seasonal variations of TWSA from GRACE and five LMIP simulations for the period 2003-2014 are presented in Fig. 6. In general, the sim-
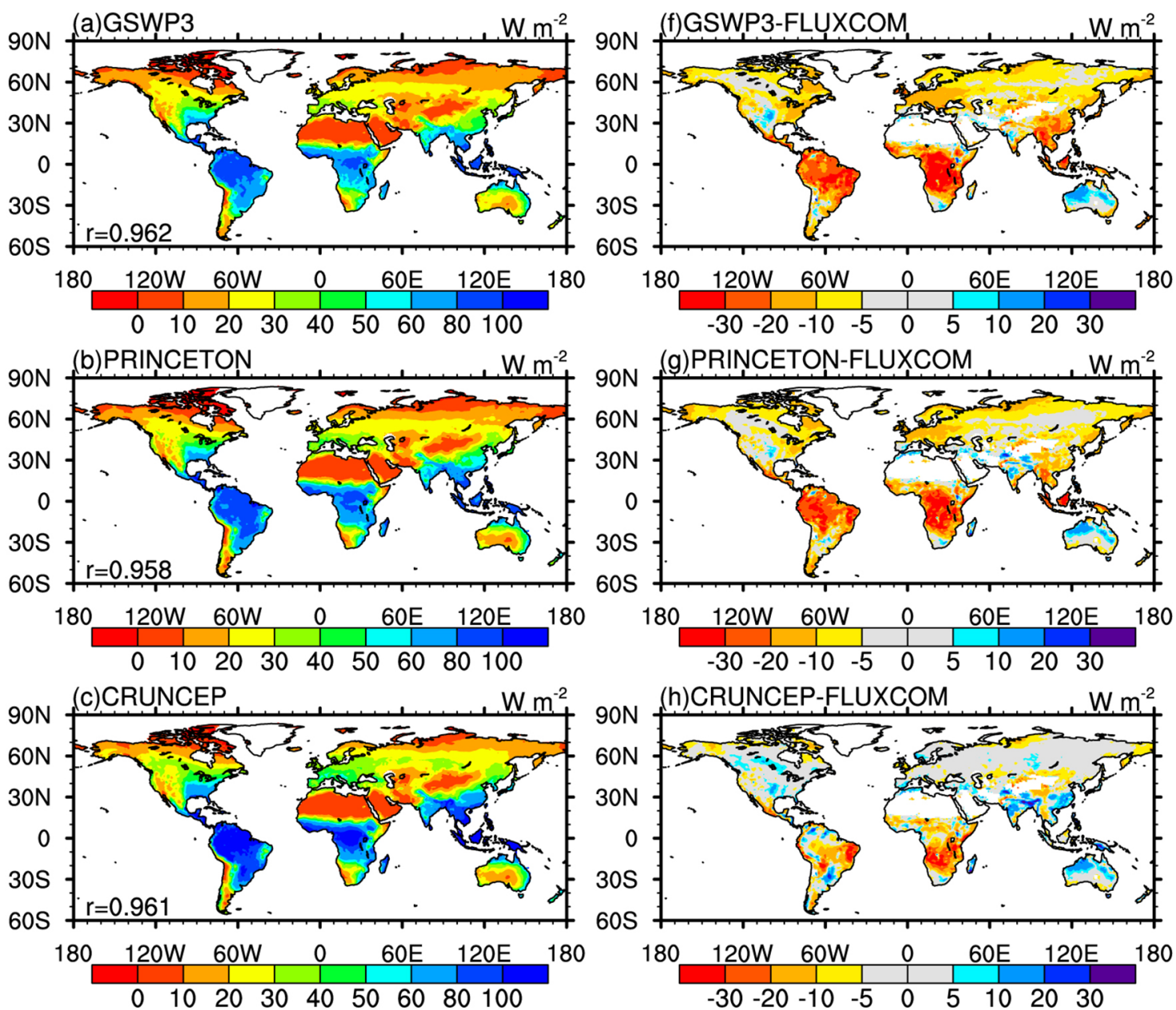

Fig. 5. Spatial patterns of latent heat flux from the five LMIP simulations (GSWP3, PRINCETON, CRUNCEP, CRUJRA, and WFDEI) and their differences with the FLUXCOM product between 2001 and 2014. The $r$ in the left column indicates the spatial correlation coefficient of the model-based simulations with FLUXCOM. 

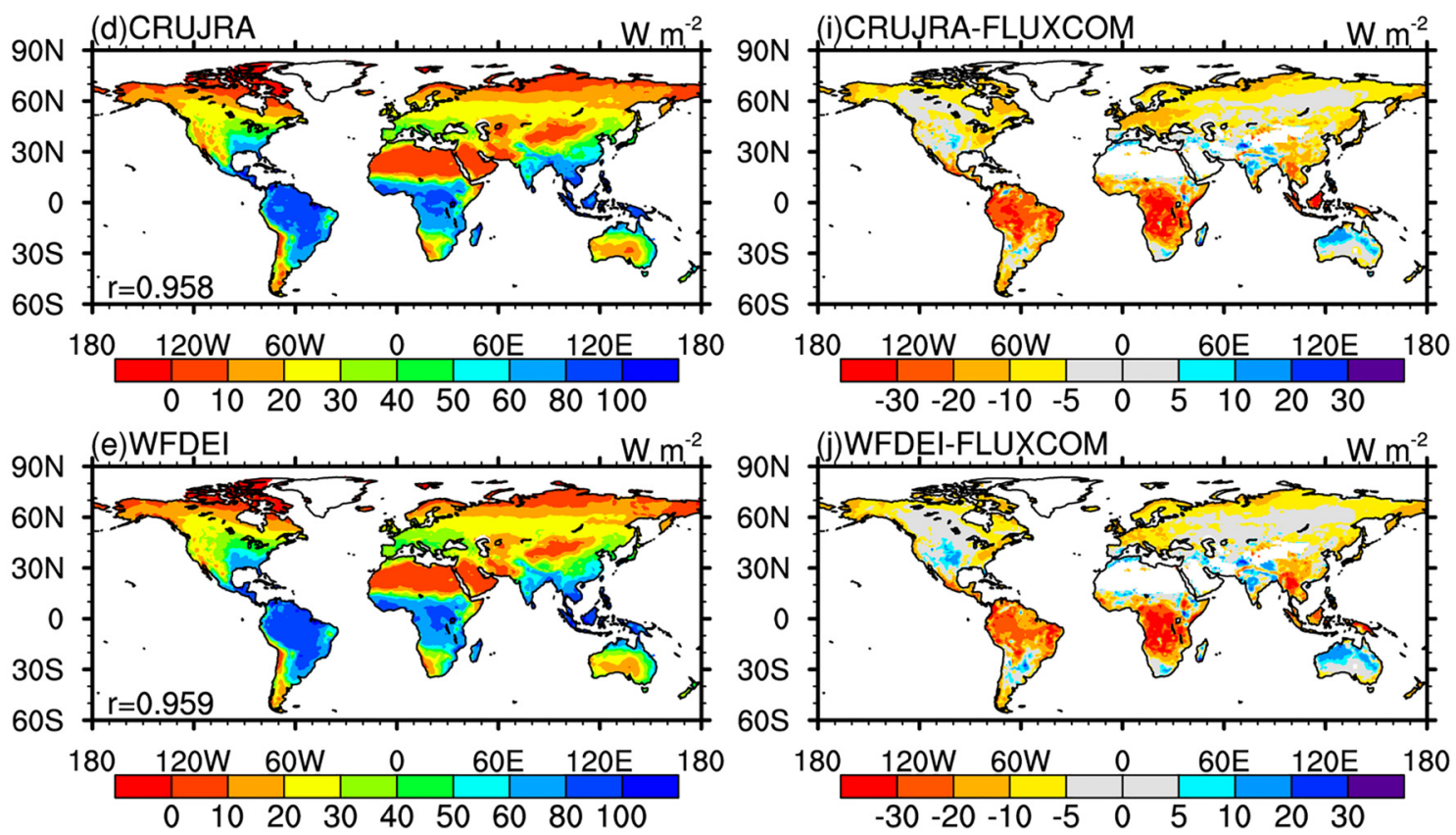

Fig. 5. (Continued).

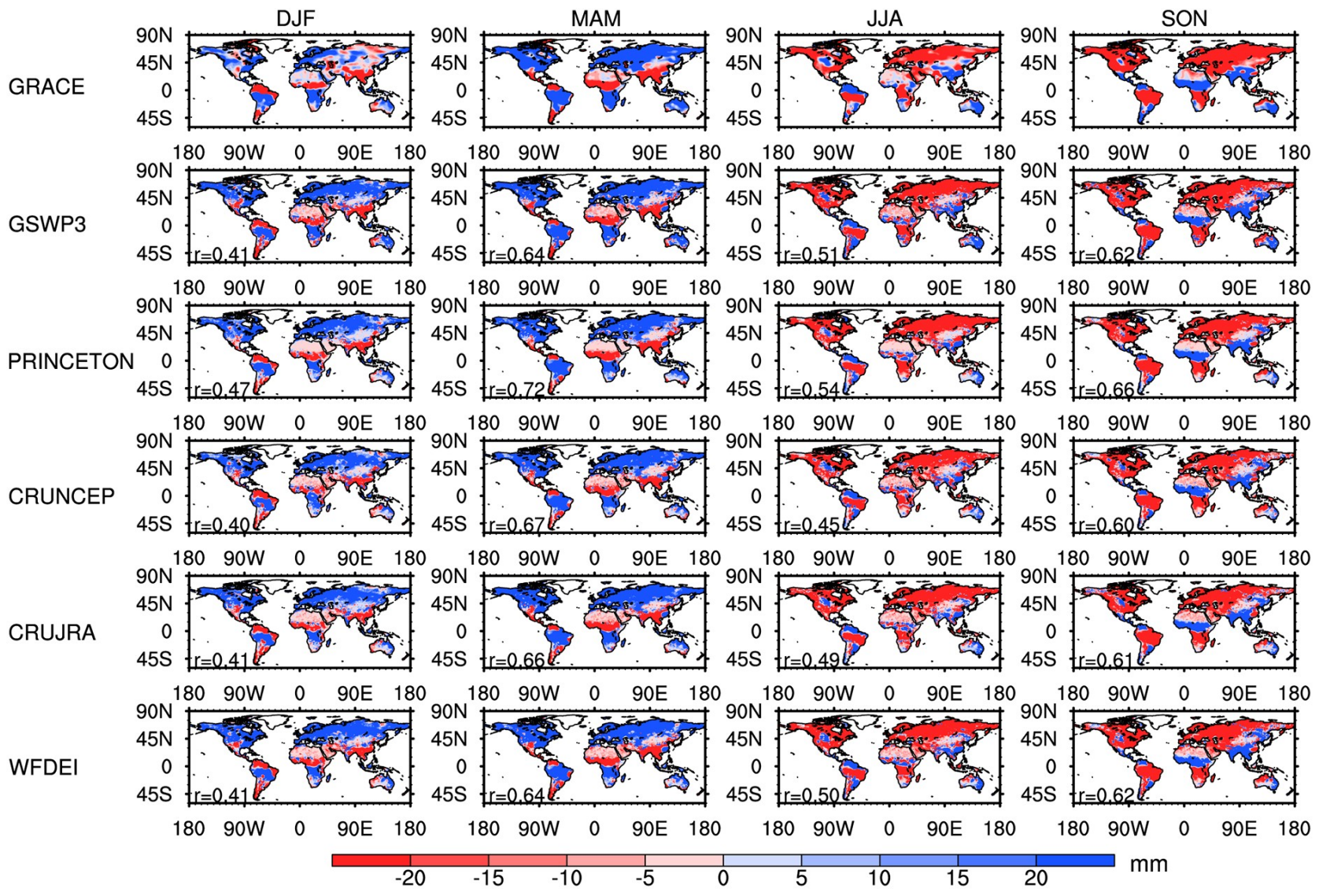

Fig. 6. Seasonal terrestrial water storage anomaly (TWSA) estimated using GRACE and simulated from the five LMIP simulations (GSWP3, PRINCETON, CRUNCEP, CRUJRA, and WFDEI) between 2003 and 2014. The $r$ indicates the spatial correlation coefficient of the model-based simulations with GRACE.

ulated seasonal patterns from CAS-LSM appear to be in good agreement with those from GRACE, with spatial correla- tion coefficients ranging between 0.40 and 0.72 . In addition, "hot spots" with significantly negative TWSA values were 
present due to groundwater overexploitation (Rodell et al., 2009; Feng et al., 2013; Sinha et al., 2017; Wang et al., 2019), such as in northern India, the North China Plain, and the central United States. These negative anomalies were detected in both the GRACE observations and the model simulations for boreal winter, spring, and summer (Fig. 6).

\section{Data records and usage notes}

Based on the meetings and seminars of participating modeling groups, the core team members of LS3MIP decided to use the CRUJRA instead of CRUNCEP (initial plan) (https://wiki.c2sm.ethz.ch/LS3MIP/LandHistWithAlternat-
iveForcingDatasets). Therefore, the four datasets for the LMIP simulations of CAS FGOALS-g3 (GSWP3, PRINCETON, CRUJRA, WFDEI) were uploaded onto the ESGF node (https://esgf-node.llnl.gov/projects/cmip6/). Note that the experiment ID of CRUJRA was still "land-histcruNcep". The model outputs have been post-processed using CMOR software and saved as the format of the Network Common Data Form (NetCDF) version 4.

The standard output of variables requested by LS3MIP (see https://wiki.c2sm.ethz.ch/LS3MIP for details) have been generated. There were 16 Priority 1 variables available on the ESGF node. Detailed information on these variables can be found in Table 2 .

Table 2. Summary of the output data tables for the LMIP of LS3MIP derived from CAS-LSM of CAS FGOALS-g3.

\begin{tabular}{|c|c|c|c|c|c|}
\hline Name & Long Name & Unit & Direction $^{\mathrm{a}}$ & $\operatorname{Dim}^{b}$ & Frequency \\
\hline huss & specific humidity & $\mathrm{kg} \mathrm{kg}^{-1}$ & - & $T Y X$ & 3-hour \\
\hline ps & surface air pressure & $\mathrm{Pa}$ & - & $T Y X$ & 3-hour \\
\hline rls & net longwave radiation & $\mathrm{W} \mathrm{m} \mathrm{m}^{-2}$ & downward & $T Y X$ & daily \\
\hline hfls & latent heat flux & $\mathrm{W} \mathrm{m} \mathrm{m}^{-2}$ & upward & $T Y X$ & daily \\
\hline hfss & sensible heat flux & $\mathrm{W} \mathrm{m}^{-2}$ & upward & $T Y X$ & daily \\
\hline tas & daily near-surface air temperature & $\mathrm{K}$ & - & $T Y X$ & daily \\
\hline tasmax & daily maximum near-surface air temperature & $\mathrm{K}$ & - & $T Y X$ & daily \\
\hline tasmin & daily minimum near-surface air temperature & $\mathrm{K}$ & - & $T Y X$ & daily \\
\hline ts & average surface temperature & $\mathrm{K}$ & - & $T Y X$ & daily \\
\hline $\mathrm{pr}$ & precipitation rate & $\mathrm{kg} \mathrm{m}^{-2} \mathrm{~s}^{-1}$ & downward & $T Y X$ & daily \\
\hline mrlsl & average layer soil moisture & $\mathrm{kg} \mathrm{m}^{-2}$ & - & $T Z Y X^{\mathrm{c}}$ & daily \\
\hline tws & terrestrial water storage & $\mathrm{kg} \mathrm{m}^{-2}$ & - & $T Y X$ & daily \\
\hline mrro & total runoff & $\mathrm{kg} \mathrm{m}^{-2} \mathrm{~s}^{-1}$ & out & $T Y X$ & daily \\
\hline $\operatorname{tran}$ & vegetation transpiration & $\mathrm{kg} \mathrm{m}^{-2} \mathrm{~s}^{-1}$ & upward & $T Y X$ & daily \\
\hline et & total evapotranspiration & $\mathrm{kg} \mathrm{m}^{-2} \mathrm{~s}^{-1}$ & upward & $T Y X$ & daily \\
\hline gwt & groundwater extraction & $\mathrm{mm} \mathrm{s}^{-1}$ & - & $T Y X$ & monthly \\
\hline
\end{tabular}

a"Direction" identifies the direction of positive numbers.

b"Dim" indicates the dimension of the variable.

c"TZYX", $T$ : time, $Y$ : latitude, $X$ : longitude, and $Z$ : soil layers (15 layers).

\section{Summary}

This paper introduced the model datasets of five LMIP experiments using CAS-LSM of CAS FGOALS-g3 within the framework of LS3MIP. Preliminary evaluation against satellite-based observations shows that CAS-LSM can reasonably capture the mean states, spatial patterns, and seasonal variations of the soil moisture, snow, and land-atmosphere energy fluxes. As one of the participating models in LS3MIP, CAS-LSM considered both the effects of HWR and the changes in the FTFs, which could enhance the performances of modeling water and energy fluxes. It improves the coupled climate system model in such a way so that it becomes a more comprehensive platform for water resource management. However, there are still some limitations in this study. Groundwater-surface water interactions have not been fully considered in the current CAS-LSM and CAS FGOALS-g3. Lastly, more in-depth evaluation against ground-based observations and comparison with other LSMs are needed in future studies.
Acknowledgements. This work was supported by the Second Tibetan Plateau Scientific Expedition and Research Program (STEP) (Grant No. 2019QZKK0206), the Youth Innovation Promotion Association CAS, the National Natural Science Foundation of China (Grant No. 41830967), and National Key Scientific and Technological Infrastructure project "Earth System Science Numerical Simulator Facility" (EarthLab). We would like to thank the editors and three reviewers for their helpful comments that improved the manuscript.

\section{Data availability statement}

The data in support of the findings of this study are available from https://esgf-node.llnl.gov/projects/cmip6/.

The citation for LS3MIP of CAS FGOALS-g3 is "CAS FGOALS-g3 model output prepared for CMIP6 LS3MIP. Earth System Grid Federation. https://doi.org/10.22033/ ESGF/CMIP6.2052".

The citation for land-hist-gswp3 is "CAS FGOALS-g3 model output prepared for CMIP6 LS3MIP land-hist. Earth 
System Grid Federation. https://doi.org/10.22033/ESGF/ CMIP6.3370".

The citation for land-hist-princeton is "CAS FGOALSg3 model output prepared for CMIP6 LS3MIP land-hist-princeton. Earth System Grid Federation. https://doi.org/10. 22033/ESGF/CMIP6.3378".

The citation for land-hist-crujra is "CAS FGOALS-g3 model output prepared for CMIP6 LS3MIP land-histcruNcep. Earth System Grid Federation. https://doi.org/ 10.22033/ESGF/CMIP6.3376".

The citation for land-hist-wfdei is "CAS FGOALS-g3 model output prepared for CMIP6 LS3MIP land-hist-wfdei. Earth System Grid Federation. https://doi.org/10.22033/ ESGF/CMIP6.3380".

The CRUNCEP simulations are available upon request. Please contact Binghao JIA at bhjia@mail.iap.ac.cn.

The ESA CCI soil moisture data were downloaded from http://www.esa-soilmoisture-cci.org. The MODIS snow cover fraction data were downloaded from https:// nsidc.org/data/MOD10CM/versions/6. The FLUXCOM data were downloaded from the Data Portal of the Max Planck Institute for Biogeochemistry (https://www.bgcjena.mpg.de/geodb/projects/Home.php). GRACE mascon CSR RL06 data were downloaded from http://www2.csr. utexas.edu/grace.

\section{Disclosure statement}

No potential conflict of interest was reported by the authors.

Electronic supplementary material: Supplementary material is available in the online version of this article at https://doi.org/ 10.1007/s00376-021-0293-x.

Open Access This article is distributed under the terms of the Creative Commons Attribution License which permits any use, distribution, and reproduction in any medium, provided the original author(s) and the source are credited. This article is distributed under the terms of the Creative Commons Attribution 4.0 International License (http://creativecommons.org/licenses/by/4.0/), which permits unrestricted use, distribution, and reproduction in any medium, provided you give appropriate credit to the original author(s) and the source, provide a link to the Creative Commons license, and indicate if changes were made.

\section{REFERENCES}

Boone, A., and Coauthors, 2009: The AMMA Land Surface Model Intercomparison Project (ALMIP). Bull. Amer. Meteor. Soc., 90(12), 1865-1880, https://doi.org/10.1175/2009 BAMS2786.1.

Compo, G. P., and Coauthors, 2011: The twentieth century reanalysis project. Quart. J. Roy. Meteor. Soc., 137(654), 1-28, https://doi.org/10.1002/qj.776.

Decharme, B., and Coauthors., 2019: Recent changes in the ISBA-CTRIP land surface system for use in the CNRMCM6 climate model and in global off-line hydrological applications. Journal of Advances in Modeling Earth Systems, 11,
1207-1252, https://doi.org/10.1029/2018MS001545.

Dorigo, W., and Coauthors, 2017: ESA CCI soil moisture for improved Earth system understanding: State-of-the art and future directions. Remote Sensing of Environment, 203, 185-215, https://doi.org/10.1016/j.rse.2017.07.001.

Eyring, V., S. Bony, G. A. Meehl, C. A. Senior, B. Stevens, R. J. Stouffer, and K. E. Taylor, 2016: Overview of the Coupled Model Intercomparison Project Phase 6 (CMIP6) experimental design and organization. Geoscientific Model Development, 9, 1937-1958, https://doi.org/10.5194/gmd-9-19372016.

Gao, J. Q., and Coauthors, 2019: A new frozen soil parameterization including frost and thaw fronts in the community land model. Journal of Advances in Modeling Earth Systems, 11, 659-679, https://doi.org/10.1029/2018MS001399.

Gruber, A., W. A. Dorigo, W. Crow, and W. Wagner, 2017: Triple collocation-based merging of satellite soil moisture retrievals. IEEE Transactions on Geoscience and Remote Sensing, 55(12), 6780-6792, https://doi.org/10.1109/TGRS. 2017.2734070.

Gruber, A., T. Scanlon, R. van der Schalie, W. Wagner, and W. Dorigo, 2019: Evolution of the ESA CCI Soil Moisture climate data records and their underlying merging methodology. Earth System Science Data, 11, 717-739, https://doi.org/10.5194/essd-11-717-2019.

Hall, D. K., and G. A. Riggs, 2015: MODIS/Terra snow cover monthly L3 global 0.05Deg CMG, version 6. NASA National Snow and Ice Data Center, Boulder, Colorado, USA. https://doi.org/10.5067/MODIS/MOD10CM.006.

Harris, I. C., 2019: CRU JRA v2.0: A forcings dataset of gridded land surface blend of Climatic Research Unit (CRU) and Japanese Reanalysis (JRA) Data; Jan. 1901-Dec. 2018. University of East Anglia Climatic Research Unit, Centre for Environmental Data Analysis. [Available from https://catalogue.ceda.ac.uk/uuid/7f785c0e80aa4df2b39d068ce7351 bbb]

Hurtt, G. C., and Coauthors, 2011: Harmonization of land-use scenarios for the period 1500-2100: 600 years of global gridded annual land-use transitions, wood harvest, and resulting secondary lands. Climatic Change, 109, 117-161, https://doi.org/ 10.1007/s10584-011-0153-2.

Feng, W., M. Zhong, J. M. Lemoine, R. Biancale, H. T. Hsu, and J. Xia, 2013: Evaluation of groundwater depletion in North China using the gravity recovery and climate experiment (GRACE) data and ground-based measurements. Water Res. Res., 49, 2110-2118, https://doi.org/10.1002/wrcr.20192.

Jia, B. H., X. M. Cai, F. Zhao, J. G. Liu, S. Chen, X. Luo, Z. H $\mathrm{Xie}$, and J. H. Xu, 2020: Potential future changes of terrestrial water storage based on climate projections by ensemble model simulations. Advances in Water Resources, 142, 103635, https://doi.org/10.1016/j.advwatres.2020.103 635.

Jung, M., and Coauthors, 2019: The FLUXCOM ensemble of global land-atmosphere energy fluxes. Scientific Data, 6, 74, https://doi.org/10.1038/s41597-019-0076-8.

Kim, H., 2017: Global soil wetness project phase 3 atmospheric boundary conditions (Experiment 1). Data Integration and Analysis System (DIAS). [Available from https://doi.org/10.20783/DIAS.501]

Lawrence, D. M., and Coauthors, 2019: The community land model version 5: Description of new features, benchmarking, and impact of forcing uncertainty. Journal of Advances in Modeling Earth Systems, 11, 4245-4287, https://doi.org/ 10.1029/2018MS001583.

Li, L. J., and Coauthors, 2020: The flexible global ocean-atmo- 
sphere-land system model grid-point version 3 (FGOALSg3): Description and evaluation. Journal of Advances in Modeling Earth Systems, 12, e2019MS002012, https://doi.org/10. 1029/2019MS002012.

Li, W. P., Y. W. Zhang, X. L. Shi, W. Y. Zhou, A. N. Huang, M. Q. Mu, B. Qiu, and J. J. Ji, 2019: Development of land surface model BCC_AVIM2. 0 and its preliminary performance in LS3MIP/CMIP6. Journal of Meteorological Research, 33(5), 851-869, https://doi.org/10.1007/s13351019-9016-y.

Lin, P. F., and Coauthors, 2020: LICOM model datasets for the CMIP6 ocean model intercomparison project. Adv. Atmos. Sci., 37, 239-249, https://doi.org/10.1007/s00376-019-92 08-5.

Oleson, K. W., and Coauthors, 2013: Technical description of version 4.5 of the community land model (CLM). NCAR/TN503+STR, Boulder, CO: NCAR.

$\mathrm{Pu}, \mathrm{Y}$., and Coauthors, 2020: CAS FGOALS-g3 model datasets for the CMIP6 Scenario Model Intercomparison Project (ScenarioMIP). Adv. Atmos. Sci., 37(10), 1081-1092, https://doi.org/10.1007/s00376-020-2032-0.

Rodell, M., I. Velicogna, and J. S. Famiglietti, 2009: Satellitebased estimates of groundwater depletion in India. Nature, 460(7258), 999-1002, https://doi.org/10.1038/nature08238.

Save, H., 2019: CSR GRACE RL06 mascon solutions. Texas Data Repository Dataverse, V1, https://doi.org/10.18738/ T8/UN91VR.

Save, H., S. Bettadpur, and B. D. Tapley, 2016: High-resolution CSR GRACE RL05 mascons. J. Geophys. Res., 121, 7547-7569, https://doi.org/10.1002/2016JB013007.

Sheffield, J., G. Goteti, and E. F. Wood, 2006: Development of a 50 -year high-resolution global dataset of meteorological forcings for land surface modeling. J. Climate, 19, 3088-3111, https://doi.org/10.1175/JCLI3790.1.

Siebert, S., P. Döll, J. Hoogeveen, J. M. Faures, K. Frenken, and S. Feick, 2005: Development and validation of the global map of irrigation areas. Hydrology and Earth System Sciences, 9, 535-547, https://doi.org/10.5194/hess-9-535-2005.

Sinha, D., T. H. Syed, J. S. Famiglietti, J. T. Reager, and R. C. Thomas, R.C., 2017: Characterizing drought in India using GRACE observations of terrestrial water storage deficit. $J$. Hydrometeorol., 18, 381-396, https://doi.org/10.1175/JHMD-16-0047.1.

Syed, T. H., J. S. Famiglietti, M. Rodell, J. N. Chen, and C. R. Wilson, 2008: Analysis of terrestrial water storage changes from GRACE and GLDAS. Water Resour. Res., 44, W02433, https://doi.org/10.1029/2006WR005779.

Tapley, B. D., S. Bettadpur, J. C. Ries, P. F. Thompson, and M. M. Watkins, 2004: GRACE measurements of mass variability in the Earth system. Science, 305, 503-505, https://doi.org/10.1126/science.1099192.

van den Hurk, B., M. Best, P. Dirmeyer, A. Pitman, J. Polcher, and J. Santanello, 2011: Acceleration of Land Surface Model development over a decade of glass. Bull. Amer. Meteor. Soc., 92(12), 1593-1600, https://doi.org/10.1175/BA MS-D-11-00007.1.

van den Hurk, B., and Coauthors, 2016: LS3MIP (v1.0) contribution to CMIP6: The Land surface, snow and soil moisture model intercomparison project-aims, setup and expected outcome. Geoscientific Model Development, 9, 2809-2832, https://doi.org/10.5194/gmd-9-2809-2016.

Viovy, N. 2018: CRUNCEP version 7 - atmospheric forcing data for the community land model. Research Data Archive at the
National Center for Atmospheric Research, Computational and Information Systems Laboratory. [Available from https: //doi.org/10.5065/PZ8F-F017]

Wang, L. H., Z. H. Xie, B. H. Jia, J. B. Xie, Y. Wang, B. Liu, R. C. Li, and S. Chen, 2019: Contributions of climate change and groundwater extraction to soil moisture trends. Earth System Dynamics, 10, 599-615, https://doi.org/10.5194/esd-10599-2019.

Wang, Y., Z. H. Xie, B. H. Jia, L. H. Wang, R. C. Li, B. Liu, S. Chen, J. B. Xie, and P. H. Qin, 2020b: Sensitivity of snow simulations to different atmospheric forcing data sets in the land surface model CAS-LSM. J. Geophys. Res., 125, e2019JD032001, https://doi.org/10.1029/2019JD032001.

Wang, Y. Q., and Coauthors, 2020a: FGOALS-g3 model datasets for CMIP6 flux-anomaly-forced model intercomparison project. Adv. Atmos. Sci., 37(10), 1093-1101, https://doi.org/ 10.1007/s00376-020-2045-8.

Weedon, G. P., and Coauthors, 2011: Creation of the WATCH Forcing Data and its use to assess global and regional reference crop evaporation over land during the twentieth century. Journal of Hydrometeorology, 12(5), 823-848, https://doi.org/10.1175/2011jhm1369.1.

Weedon, G. P., G. Balsamo, N. Bellouin, S. Gomes, M. J. Best, and P. Viterbo, 2014: The WFDEI meteorological forcing data set: WATCH forcing data methodology applied to ERA-interim reanalysis data. Water Resour. Res., 50(9), 7505-7514, https://doi.org/10.1002/2014wr015638.

Xie, Z. H., and Coauthors, 2018a: A high-resolution land model with groundwater lateral flow, water use and soil freezethaw front dynamics and its applications in an endorheic basin. J. Geophys. Res.-Atmos., 7204-7222, https://doi.org/ 10.1029/2018JD028369123.

Xie, Z. P., Z. Y. Hu, Z. H. Xie, B. H. Jia, G. H. Sun, Y. Z. Du, and H. Q. Song, 2018b: Impact of the snow cover scheme on snow distribution and energy budget modeling over the Tibetan Plateau. Theor. Appl. Climatol., 131, 951-965, https://doi.org/10.1007/s00704-016-2020-6.

Yoshimura, K., and M. Kanamitsu, 2008: Dynamical global downscaling of global reanalysis. Mon. Wea. Rev., 136(8), 2983-2998, https://doi.org/10.1175/2008mwr2281.1.

Zeng, N., J. H. Yoon, A. Mariotti, and S. Swenson, 2008: Variability of basin-scale terrestrial water storage from a PER water budget method: The amazon and the Mississippi. J. Climate, 21, 248-265, https://doi.org/10.1175/2007JCLI1639.1.

Zeng, Y. J., Z. H. Xie, Y. Yu, S. Liu, L. Y. Wang, J. Zou, P. H. Qin, and B. H. Jia, 2016: Effects of anthropogenic water regulation and groundwater lateral flow on land processes. Journal of Advances in Modeling Earth Systems, 8, 1106-1131, https://doi.org/10.1002/2016MS000646.

Zeng, Y. J., Z. H. Xie, and J. Zou, 2017: Hydrologic and climatic responses to global anthropogenic groundwater extraction. $J$. Climate, 30, 71-90, https://doi.org/10.1175/JCLI-D-160209.1.

Zheng, W. P., and Coauthors, 2020: CAS-FGOALS datasets for the two interglacial epochs of the Holocene and the Last Interglacial in PMIP4. Adv. Atmos. Sci., 37(10), 1034-1044, https://doi.org/10.1007/s00376-020-9290-8.

Zou, J., Z. H. Xie, C. S. Zhan, P. H. Qin, Q. Sun, B. H. Jia, and J. Xia, 2015: Effects of anthropogenic groundwater exploitation on land surface processes: A case study of the Haihe River Basin, northern China. Journal of Hydrology, 524, 625-641, https://doi.org/10.1016/j.jhydrol.2015.03.026. 